\title{
Association between MMP1 and MMP9 activities and ICAM1 cleavage induced by tumor necrosis factor in stromal cell cultures from eutopic endometria of women with endometriosis
}

\author{
M Pino ${ }^{1}$, C Galleguillos ${ }^{1}, \mathrm{M}$ Torres $^{1}$, H Sovino ${ }^{1,2}$, A Fuentes ${ }^{1,2}$, M A Boric ${ }^{1}$ and M C Johnson ${ }^{1}$ \\ ${ }^{1}$ Institute of Maternal and Child Research, Faculty of Medicine, University of Chile, PO Box 226-3, Santiago, Chile \\ and ${ }^{2}$ San Borja Arriarán Clinical Hospital, Santiago, Chile
}

Correspondence should be addressed to M C Johnson; Email: cjohnson@med.uchile.cl

\begin{abstract}
Endometriosis is a benign gynecological pathology in which immune system deregulation may play a role in its initiation and progression. In endometriotic lesions, intercellular adhesion molecule-1 (ICAM1) is released from the cell membrane by proteolytic cleavage of its extracellular domain, a process that coincides with increased expression and proteolytic activity of metalloproteinases such as MMP1 and MMP9. The objective of our study was to investigate the association between MMP1 and MMP9 activities and ICAM1 cleavage mediated by tumor necrosis factor (TNF) in eutopic endometrial stromal cells from women with and without (control) endometriosis during culture. The RNA was evaluated by RT-PCR, and the protein was determined by western blot (ICAM1, MMP1), casein or gelatin zymographies (secreted active MMP1 or MMP9 respectively), ELISA (soluble ICAM1 (sICAM1)), and fluorescence assay (secreted active MMP1). Under basal conditions, proMMP9 dimer and MMP9 were higher in endometriosis cell cultures. In stromal cultures derived from control women and those with endometriosis, TNF augmented the intracellular proMMP1 (1.2-fold in control stromal cells) and ICAM1 (1.4- and 1.9-fold), greatly increased MMP1 and proMMP9 levels, and the sICAM1 concentration (2.3- and 4.3-fold) in their media compared with basal levels. The combination of TNF and MMP9 increased the sICAM1 concentration 14-fold in the endometriosis cell media, whereas GM6001 inhibited the stimulatory effect of TNF in both cell cultures. The deregulation of MMP9, and the TNF participation in the MMP1 and proMMP9 secretions, in the MMP9 expression and in the expression and cleavage of ICAM1 may contribute to the pathophysiology of this disease.

Reproduction (2009) 138 837-847
\end{abstract}

\section{Introduction}

Endometriosis is a benign invasive gynecological pathology characterized by the presence of endometrial tissue outside the uterine cavity. It affects nearly $10 \%$ of women of reproductive age, and it is associated with progressive dysmenorrhea, dyspareunia, chronic pelvic pain, and infertility (Cramer \& Missmer 2002, Murphy 2002, Bulun 2009). Despite the fact that this disease has gained increasing interest in recent years, with over 10000 scientific publications on the topic, its etiology still remains unknown, with the retrograde menstruation theory being the most broadly accepted explanation (Sampson 1927).

Additionally, the immune system plays a key role in the pathophysiology of endometriosis, and its deregulation permits the escape, implantation, and proliferation of endometrial cells that have invaded the pelvic cavity via retrograde menstruation. For those mechanisms to occur, the invading endometrial cells need to establish cell-cell or cell-extracellular matrix interactions with the peritoneal surface. Cell adhesion molecules (CAM), important mediators of these interactions, are functional receptors expressed on the cell membrane that participate actively in multiple physiological processes, such as leukocyte migration and activation, and also in pathological processes, such as tumor dissemination and metastasis (Dejana 2004, Gavert et al. 2007, Fan et al. 2009). Endometrial cells normally express adhesion molecules such as intercellular adhesion molecule-1 (ICAM1), a 90 kDa glycoprotein member of the immunoglobulin family, which is constitutively expressed by epithelial cells; however, it is expressed in a regulated pattern by stromal cells from endometrium during the menstrual cycle (Thomson et al. 1999). ICAM1 function is related to the interaction between ICAM1 positive cells and cells from the immune system through the antigen lymphocyte function-associated antigen-1 (ITGAL) expressed on the leukocyte surface, modulating the 
cytotoxic activity of CD8 + leucocytes and natural killer (NK) cells (Rothlein et al. 1988, Tabibzadeh et al. 1994, Vigano et al. 1994). Alteration of the interaction between ITGAL and ICAM1 may be one of the crucial stimuli for the initiation and progression of endometriosis (Oosterlynck et al. 1991). In recent years, the role of soluble ICAM1 (sICAM1) has been studied in detail because of its role in the development of cancer. Tumoral cells release this molecule, which conserves its binding capacity to the ITGAL antigen and competes with membrane-bound ICAM1, reducing the amount of leucocytes available for the recognition of surface ICAM1 on target cells and allowing the target cells to escape from leukocyte surveillance. In endometriosis, the concentration of sICAM1 released from endometrial cells and the augmented levels of this molecule in the peritoneal fluid show a direct and significant association with the inhibition of the cytotoxic activity of NK cells, the severity of endometriosis, and the type of endometriotic lesion (Somigliana et al. 1996, Kupker et al. 1998, Gonzalez-Ramos et al. 2007).

In endometriotic lesions, ICAM1 is released from the cell membrane by proteolytic cleavage of its extracellular domain, with a parallel increase in expression and proteolytic activity of certain MMPs, including MMP1 and MMP9 (Vigano et al. 1998, Chung et al. 2001, Mizumoto et al. 2002, Hudelist et al. 2005). MMP1 shows altered levels in culture supernatants of uterine endometrial cells from patients with endometriosis compared with the endometria from healthy women (Sillem et al. 2001), and a positive correlation between its altered secretion and the development and activity of endometriotic foci has been described (Kokorine et al. 1997). Besides, it has been suggested that ICAM1 could increase MMP1 expression in cultured fibroblasts (Domeij et al. 2005) and that it might activate other MMPs, such as MMP9 (Chakraborti et al. 2003). Regarding MMP9, augmentation of its activity in pathological processes has been reported to favor the progression of neoplasias, whereas its diminution inhibits the invasion of tumor cells both in vivo and in vitro (Declerck et al. 1992, Fishman et al. 1997). In eutopic and ectopic endometria from women with endometriosis, the activity of MMP9 might be augmented, thus favoring their potential proteolytic activity and tissue invasion (Chung et al. 2001, Liu et al. 2002, Collette et al. 2004, 2006). The peritoneal fluid of these patients contains an elevated concentration of MMP9 with concomitant reduction in tissue inhibitor of metalloproteinases-1 (TIMP1), which favors its proteolytic activity, the degradation of the peritoneum and tissue invasion (Szamatowicz et al. 2002). Tumor cell studies have demonstrated the participation of MMP9 in the cleavage of ICAM1; thus, it contributes to tumor resistance against NK cell cytotoxic activity (Fiore et al. 2002).

Tumor necrosis factor $\alpha$ (TNF), a pleiotropic cytokine produced by several cell types, plays a role in proinflammatory diseases, and its abnormal production may contribute to the pathophysiology of endometriosis, favoring cell proliferation and tissue adhesion. Among the molecules regulated by TNF are ICAM1, MMP1, and MMP9, which are probably regulated through the NFKB1 pathway; all of these molecules are deregulated in endometria from women with endometriosis (Ulukus et al. 2006).

In this study, we investigated the associations between MMP1, MMP9, and ICAM1 mediated by TNF in endometrial stromal cells obtained from women with and without endometriosis.

\section{Results \\ MMP1, MMP9, and ICAM1 mRNA in stromal cell cultures}

The MMP1, MMP9, ICAM1 mRNA levels were detected in control and endometriosis stromal cells with or without TNF (Table 1). MMP1 mRNA expression was significantly higher in stromal cell cultures derived from control women (control cells) than those with endometriosis (endometriosis cells), and the addition of TNF did not affect its expression. The mRNA levels of MMP9 were significantly increased by 2.8 - and 1.7 -fold in the presence of TNF in both stromal cell cultures respectively being also higher in stromal cells from controls than from endometriosis patients. The mRNA of ICAM1 was not statistically different in basal condition, but in the presence of TNF it was 2.0-fold greater in stromal control cells than in endometriosis cells $(P<0.05)$.

Table 1 ICAM1, MMP1, and MMP9 mRNA in stromal cell cultures.

\begin{tabular}{|c|c|c|c|c|c|c|}
\hline & \multicolumn{2}{|c|}{ MMP1 } & \multicolumn{2}{|c|}{ MMP9 } & \multicolumn{2}{|c|}{ ICAM1 } \\
\hline & Control & Endometriosis & Control & Endometriosis & Control & Endometriosis \\
\hline Basal & $1.08 \pm 0.17$ & $0.63 \pm 0.09 *$ & $0.33 \pm 0.07$ & $0.21 \pm 0.06$ & $0.76 \pm 0.11$ & $0.44 \pm 0.11$ \\
\hline TNF & $1.05 \pm 0.14$ & $0.63 \pm 0.06$ & $1.25 \pm 0.13^{\dagger}$ & $0.57 \pm 0.10^{*,+}$ & $1.10 \pm 0.09$ & $0.36 \pm 0.02 *$ \\
\hline
\end{tabular}

The stromal cell cultures were incubated in basal conditions or with TNF $(10 \mathrm{ng} / \mathrm{ml})$ for $24 \mathrm{~h}$. Results are the mean \pm s.E.M. of twelve stromal cell cultures obtained from six controls (two proliferative and four secretory) and six endometriosis (one proliferative and five secretory) endometria. Significant difference $* P<0.05$ respect to control; ${ }^{\dagger} P<0.05$ respect to basal. 


\section{Protein content and activity of MMP1 in endometrial stromal cell cultures}

The MMP1 protein content was studied in cytosolic homogenates by western blot, and its activity was determined in cell culture medium by casein zymography. In control and endometriosis stromal cell homogenates, only proMMP1 was detected, even though the antibody recognizes both the pro- and the active enzymes. Under basal conditions, although proMMP1 content was greater in endometriosis cells than in control cells, this was not significantly different. Similar results were obtained when the stromal cells cultures were separated in proliferative and secretory phase (control: $0.22 \pm 0.12$ and $0.36 \pm 0.02 \mathrm{AU}$; endometriosis: $0.38 \pm 0.3$ and $0.44 \pm 0.09 \mathrm{AU}$ respectively). The addition of TNF increased significantly its content only in the control cultures by 1.2-fold compared with basal levels (Fig. 1).

Active MMP1 secreted into the medium during culture was detected at low levels by casein zymography in control and in endometriosis cells cultured under basal conditions, and no differences were observed between stromal cells obtained from proliferative or secretory endometria. On the contrary, the TNF treatment strongly induced the secretion of active MMP1 in both cell cultures $(P<0.05$ compared with the basal), with a strong $51 \mathrm{kDa}$ band and a slightly larger $53 \mathrm{kDa}$ band corresponding to MMP1 and proMMP1 respectively (Fig. 2A). These results were confirmed by western blot (Fig. 2B). This TNF-mediated increase in active MMP1 secreted into the media is shown in Fig. 2C. Similar results were obtained measuring the concentration of active MMP1 by a fluorescence assay in the cell media under basal conditions (control: $0.802 \pm 0.57$ and endometriosis: $0.215 \pm 0.15 \mathrm{ng} / \mu \mathrm{g}$ protein) and after TNF treatment, with an increase of 20-fold in both control $(n=3)$ and endometriosis $(n=3)$ stromal cells compared with basal levels $(P<0.05)$.

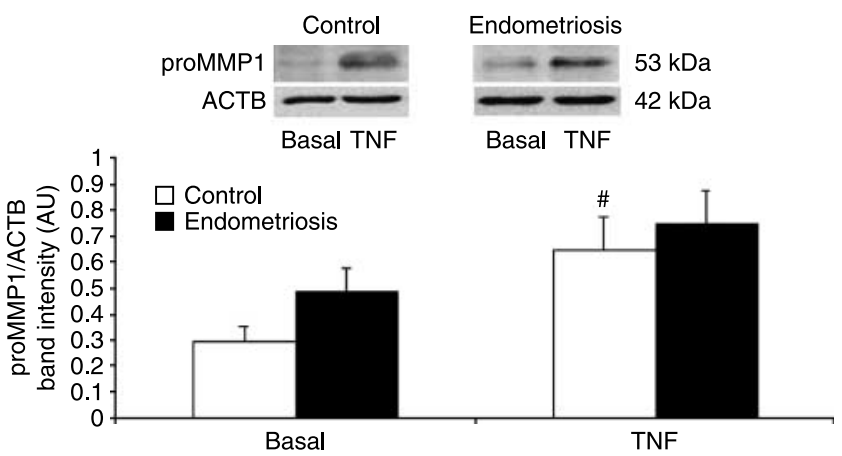

Figure 1 Protein content of proMMP1 in endometrial stromal cell cultures. Cytosolic homogenates of cells incubated in basal condition or with TNF $(10 \mathrm{ng} / \mathrm{ml})$ for $48 \mathrm{~h}$. Representative gel is shown. Values normalized with ACTB are expressed as mean \pm s.E.M. for eight controls (three proliferative and five secretory phase) and eight endometriosis (two proliferative and six secretory phase) cell cultures obtained from sixteen endometria.

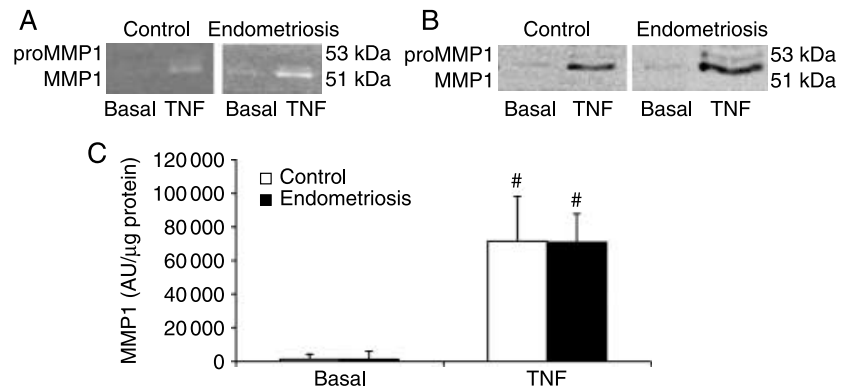

Figure $2 \mathrm{MMP} 1$ activity and protein content secreted into the endometrial stromal cell media. Casein zymography (A and C) or western blot (B) of media from stromal cell cultures incubated in basal condition or with TNF $(10 \mathrm{ng} / \mathrm{ml})$ for $48 \mathrm{~h}$. Representative gels are shown. Values normalized by microgram of total protein $(\mathrm{C})$ are expressed as mean \pm S.E.M. obtained from eight controls (three proliferative and five secretory phase) and eight endometriosis (two proliferative and six secretory phase) obtained from sixteen endometria. ${ }^{*} P<0.05$ with respect to basal.

\section{Secretion and activity of MMP9 in endometrial stromal cell cultures}

MMP9 secreted into the media of stromal cell cultures from control and endometriosis endometria was detected as three bands corresponding to putative proMMP9 dimer (170 kDa), proMMP9 (92 kDa), and active MMP9 (82 kDa) by gelatin zymography (Fig. 3A). The secretion of proMMP9 dimer was detected under basal conditions in both control and endometriosis cells being 2.8-fold higher in endometriosis medium than in control medium $(P<0.05)$. Although the active MMP9 was strongly detected in endometriosis media compared with control media, no significant differences were obtained when the MMP9 data were analyzed neither altogether (Fig. 2B) nor separated in proliferative and secretory phase (control: $1.02 \pm 0.3$ and $0.71 \pm 0.19$; endometriosis: $1.88 \pm 1.3$ and $3.86 \pm 2.3 \mathrm{AU}$ respectively). The addition of TNF did not modify their secretion into control and endometriosis media compared with basal levels.

On the other hand, the secretion of proMMP9 was undetectable under basal conditions, but after TNF treatment, a strong secretion of the zymogen into the media from both control and endometriosis cells was obtained $(P<0.05$; Fig. $3 \mathrm{~A}$ and $\mathrm{B})$.

The MMP1 and MMP9 activities were confirmed by the incubation of some gels into MMPs assay buffer that contained EDTA $(4 \mathrm{mmol} / \mathrm{l})$, which inhibit the enzymatic activity by the absence of $\mathrm{Ca}^{2+}$ in the buffer, and the corresponding bands were not observed (data not shown).

\section{ICAM1 protein content and sICAM1 concentration in endometrial cell cultures}

Under basal conditions, similar ICAM1 protein content was observed in control and endometriosis cell homogenates, and no statistically significant differences 
A
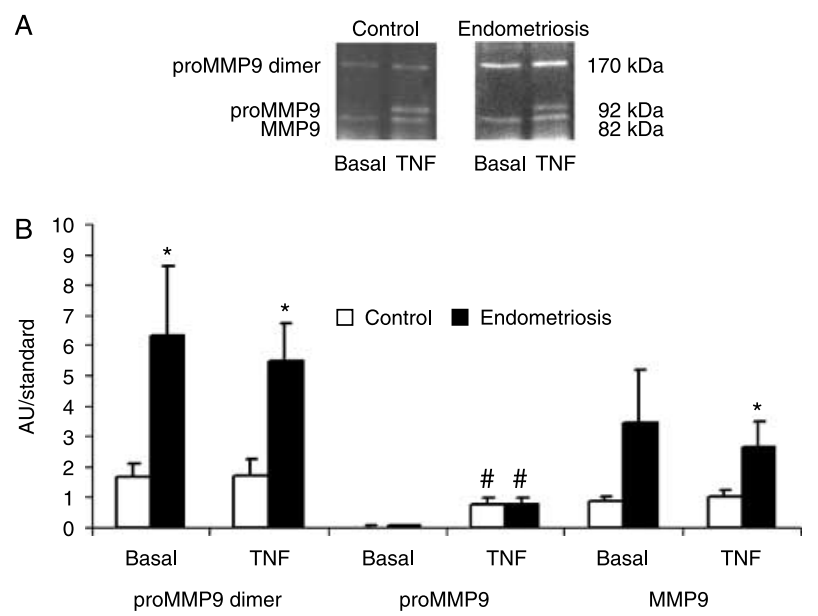

Figure 3 Secretion of proMMP9 dimer, proMMP9, and MMP9 into endometrial stromal cell media. Gelatin zymography of the media from stromal cells cultures incubated in basal condition or with TNF $(10 \mathrm{ng} / \mathrm{ml})$ for $48 \mathrm{~h}$. Representative gel is shown. Values normalized with MMP9 standard are expressed as mean \pm s.E.M. from eight controls (three proliferative and five secretory phase) and eight endometriosis (two proliferative and six secretory phase) cell cultures obtained from sixteen endometria. ${ }^{\sharp} P<0.05$ with respect to basal; ${ }^{*} P<0.05$ with respect to control.

were observed when the data were separated in proliferative and secretory endometria (control: $0.42 \pm 0.11$ and $0.77 \pm 0.21$; endometriosis: $0.3 \pm 0.2$ and $0.64 \pm 0.2 \mathrm{AU}$ respectively). TNF increased 1.4- and 1.9-fold the ICAM1 protein contents in control and endometriosis cells respectively ( $P<0.05$; Fig. 4A).

The basal concentration of sICAM1 was almost undetectable in the medium of control stromal cell cultures, whereas in endometriosis cell cultures there was a tendency towards a greater concentration of this molecule (Fig. 4B). Similar results were obtained when the sICAM1 data were separated in proliferative and secretory endometria (control: $0.18 \pm 0.05$ and $0.20 \pm 0.08 \mathrm{ng} / \mu \mathrm{g}$; endometriosis: $0.26 \pm 0.02$ and $0.41 \pm 0.18 \mathrm{ng} / \mu \mathrm{g})$. In cells treated with TNF, sICAM1 concentration increased up to 2.3- and 4.3-fold with respect to basal concentrations in the media from control and endometriosis cell cultures respectively $(P<0.05$; Fig. 4B).

\section{Association between sICAM1 and active MMP1 or active MMP9 in culture media from stromal cells}

In order to elucidate whether sICAM1 changes are associated with active MMPs, the relation between sICAM1 concentration and the activity of MMP1 or MM-9 was analyzed by the Pearson correlation test $(r)$. Under basal conditions, there was no significant association between sICAM1 and active MMP1 detected in media from control cells $(r=-0.54)$ or endometriosis cells $(r=-0.18)$; however, a positive and significant correlation was obtained between sICAM1 and active
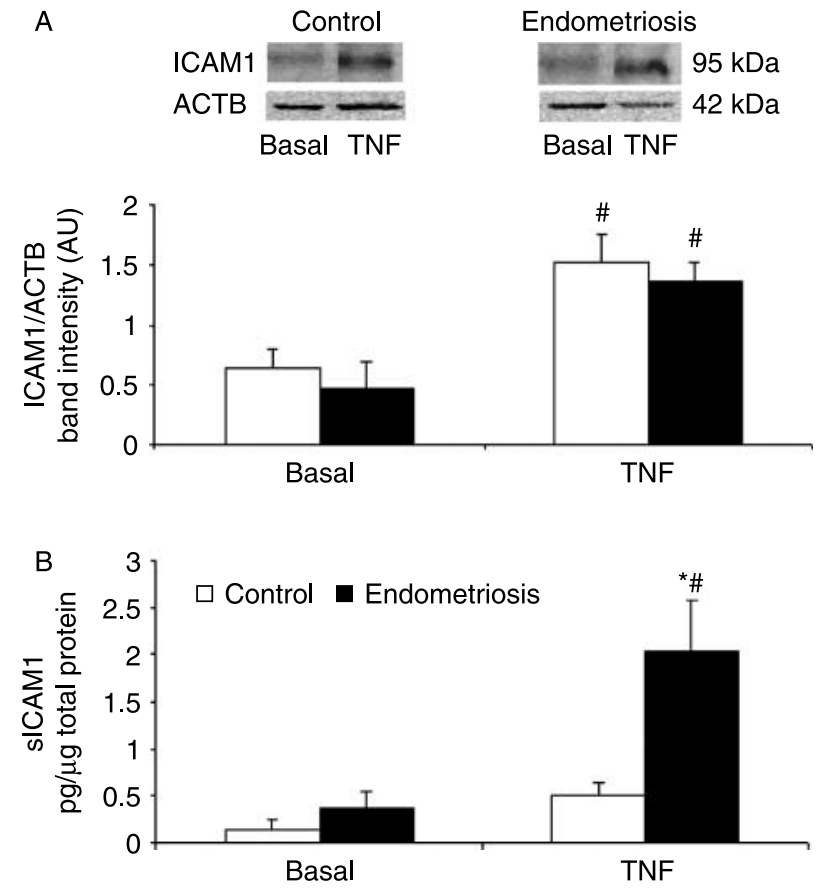

Figure 4 ICAM1 content and sICAM1 concentration in endometrial stromal cell cultures. Western blot of cellular homogenates (A) or ELISA of the media (B) from stromal cell cultures incubated in basal condition or with TNF $(10 \mathrm{ng} / \mathrm{ml})$ for $48 \mathrm{~h}$. Representative gel is shown. Values normalized with ACTB (A) or microgram of total protein (B) are expressed as mean \pm s.E.M. from eight controls (three proliferative and five secretory phase) and eight endometriosis (two proliferative and six secretory phase) cell cultures obtained from sixteen endometria.

${ }^{\#} P<0.05$ with respect to basal; ${ }^{*} P<0.05$ with respect to control.

MMP1 in the media from cells treated with TNF (Table 2). On the other hand, a positive and significant association between sICAM1 and active MMP9 in basal and TNF-treated cells was only observed in the medium from endometriosis cell cultures (Table 2).

\section{Effect of TNF, MMP1, and MMP9 on ICAM1 cleavage in stromal cell cultures}

To understand the mechanism by which MMP1 and/or MMP9 participate on the ICAM1 cleavage induced by TNF, control and endometriosis stromal cell cultures were treated with TNF and with the catalytic domain of

Table 2 Pearson's coefficient of correlation $(r)$ between soluble intercellular adhesion molecule-1 (sICAM1) and MMP1 or MMP9 in stromal cell cultures.

\begin{tabular}{lrrrrrr}
\hline & \multicolumn{2}{c}{ Control } & & \multicolumn{2}{c}{ Endometriosis } \\
\cline { 2 - 3 } \cline { 5 - 6 } & \multicolumn{2}{c}{ Basal } & TNF & & Basal & TNF \\
\hline sICAM1/MMP1 & -0.54 & $0.79^{*}$ & & -0.18 & $0.79^{*}$ \\
sICAM1/MMP9 & 0.17 & 0.16 & & $0.98^{*}$ & $0.76^{*}$
\end{tabular}

Medium was obtained from stromal cell cultures in basal conditions or treated with TNF $(10 \mathrm{ng} / \mathrm{ml})$ for $48 \mathrm{~h} .{ }^{*} P<0.05$. 


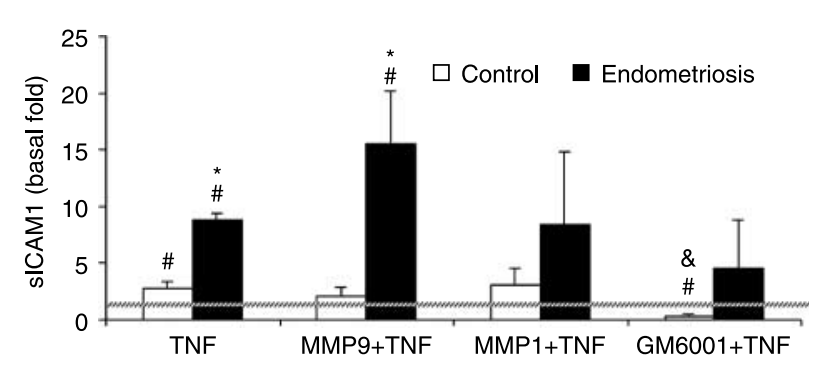

Figure 5 Effect of TNF, MMP1, and MMP9 on ICAM1 cleavage in endometrial stromal cell cultures. Media of stromal cell cultures incubated in basal condition or with TNF $(10 \mathrm{ng} / \mathrm{ml})$, MMP9 (1.3 nmol/l), MMP1 (0.7 nmol/l), or GM6001 (100 $\mu \mathrm{mol} / \mathrm{l})$ for $48 \mathrm{~h}$. Values normalized by microgram of total protein are expressed as mean \pm S.E.M. of four controls and four endometriosis cell cultures obtained from eight endometria at secretory phase. Basal values: control $0.15 \pm 0.08$ and endometriosis $0.38 \pm 0.16 \mathrm{pg} / \mu \mathrm{g}$ of protein. ${ }^{\#} P<0.05$ with respect to basal; $* P<0.05$ with respect to control; ${ }^{\&} P<0.05$ with respect to TNF.

either MMP1 or MMP9, or with the MMP specific inhibitor GM6001. The increase in sICAM1 concentration by TNF described previously was not modified by the co-incubation with the catalytic domain of MMP1 or MMP9 in control cell cultures; however, the presence of GM6001 not only completely inhibited the TNF-mediated increase in sICAM1 concentration, but it also reduced sICAM 1 concentrations by $73 \%$ compared with basal levels $(P<0.05$; Fig. 5). On the contrary, in endometriosis cell cultures, the robust increase (8.0-fold) in sICAM1 concentration produced by TNF was almost duplicated (14-fold) by the addition of the MMP9 catalytic domain $(P<0.05)$. Similar to what was observed in control cells, in endometriosis cell cultures, no significant difference was observed when TNF and the MMP1 catalytic domain were co-incubated. The inhibitor GM6001 prevented the stimulatory effect of TNF on these cells (Fig. 5).

\section{Discussion}

Considering that endometriosis is a pro-inflammatory and invasive benign disease for which the pathophysiological mechanism remains unknown, several molecules have been studied to understand its etiology. In the present report, we studied the effect of TNF on ICAM1, MMP1, and MMP9 and determined the association between the active MMP enzymes and ICAM1 cleavage using cultures of stromal cells isolated from eutopic endometria from women with or without endometriosis.

The immune system plays an important role in the development of endometriosis. Several molecular and cellular alterations have been reported in endometriosis, including augmented macrophage number with increased secretory activity but diminished phagocytic activity, the reduction in NK cell number and activity for the recognition and elimination of ectopic endometrial cells (Lebovic et al. 2001, Kyama et al. 2003, Khan et al.
2004). As previously mentioned, MMPs not only cleave the classical extracellular matrix substrates, but also cleave associated proteins of the cell membrane that, after being released, might mediate cell proliferation, apoptosis, migration, and communication among others processes (Mccawley \& Matrisian 2001). Therefore, the participation of these enzymes in the pathophysiology of endometriosis could be much broader.

Our results show that TNF induced both the protein and the activity of MMP1 in stromal endometrial cells from controls and endometriosis patients by mechanisms that have not yet been established. This study was performed at 24 and $48 \mathrm{~h}$ of cultures, a time frame that is probably sufficient for both de novo mRNA synthesis and its degradation; however, we did not observe any change in MMP1 mRNA expression by TNF treatment, either for short periods ( 2 and $6 \mathrm{~h}$; data not shown) or for long periods ( 24 and $48 \mathrm{~h}$ ), and a solid band that probably corresponds to basal MMP1 mRNA level was observed at all of the times studied. These results indicate the absence of the in vivo complex negative regulation of MMP1 gene expression by progesterone described for several MMPs (Osteen et al. 1996, Henriet et al. 2002). In addition, the strong response of the intracellular and secreted MMP1 protein levels to TNF was also confirmed by a specific antibody that recognized both the pro- and the active enzymes and also by the MMP1 enzymatic activity assay. As described in other papers (Rawdanowicz et al. 1994, Henriet et al. 2002), secreted MMP1 was determined by casein zymography, a technique that also detects the proMMP3 (57 kDa) and the active MMP3 (45 kDa) enzymes. We did not observe bands attributable to MMP3 as reported by Rawdanowicz et al. (1994) who detected the co-secretion of MMP1 and MMP3 as zymogens in endometrial stromal cells from the first passage, suggesting that its gene expression may be affected by the cell passage number.

The very low MMP9 mRNA levels and the strong secretion of the active MMP9 and its proMMP9 dimer, but not of the proMMP9, in endometriosis stromal cells compared with control cell cultures suggest both posttranscriptional and posttranslation modifications of MMP9. TNF induced the MMP9 mRNA in both cell cultures in agreement with other publications (Singer et al. 1999, Collette et al. 2004); however, in contrast to these authors, who showed its maximal mRNA expression $6 \mathrm{~h}$ after TNF treatment and reduced expression at $12 \mathrm{~h}$, we couldn't detect MMP9 mRNA at 3 and $6 \mathrm{~h}$ (data not shown) but we did in cells treated for $24 \mathrm{~h}$. We cannot exclude an effect between 6 and $24 \mathrm{~h}$, as intermediate times were not analyzed. The number of passages of these reports and ours may be also a temporary factor that affects the MMP expression. Although the three forms of MMP9 or gelatinase B were detected in the cell media, the dimer and the active enzyme were the most commonly secreted forms and 
did not vary with TNF treatment. The greater amount of active MMP9 in the supernatants of cell cultures from eutopic endometrium of endometriosis patients demonstrated that the augmented proteolytic activity in these endometria would be mediated, in part, by this enzyme, a finding supported by others studies (Collette et al. 2004, 2006). Little is known about the biochemical properties and the function of the proMMP9 dimer; in mammalian cells, its intracellular dimerization and posterior secretion have been described (Olson et al. 2000), showing a greater resistance to denaturation than the monomeric form. Therefore, the fluctuations in the relative amounts of this dimer and the proenzyme might have an additional role in the control of degradation of the extracellular matrix mediated by MMP9. Gelatin zymography also detects two other bands that correspond to proMMP2 $(72 \mathrm{kDa})$ and the active MMP2, or gelatinase A $(62 \mathrm{kDa})$; we did not evaluate this enzyme in the present study because of the strong saturated bands observed after $48 \mathrm{~h}$ culture. Even though both gelatinases have similarities, MMP9 possesses unique genetic, structural, and functional regulation (Olson et al. 2000).

TNF strongly increased the content of proMMP9 secreted into the media of both stromal cell groups. Similarly, in the presence of the proper stimulus, endothelial cells release both the zymogen and the active forms of MMPs stored in cytoplasmic granules that can be quickly secreted without de novo synthesis (Taraboletti et al. 2002), processes also described in other cell types such as neutrophils, in which TNF mediates the release of the protein contained in tertiary granules through different signaling pathways (Chakrabarti et al. 2006). Therefore, the study of MMP9 protein and the secretion granules in endometrial cells are especially interesting because it would contribute to the full understanding of the mechanisms involved in this process. In addition, TNF has an important role in the deregulation of these proteases in endometriosis, with elevated levels of this cytokine in the eutopic endometrium during the secretory phase, in the peritoneum, and also in the menstrual and peritoneal fluids that correlate to the degree of pelvic adhesions (Cheong et al. 2002, Kyama et al. 2003).

One of the mechanisms by which TNF could be involved in the stimulation of MMP1 and MMP9 expression is through the NFKB1 pathway. The NFKB1 family is composed of several protein subunits that possess DNA binding and dimerization sites, and frequently found in diverse tissues that include the endometrium (Beinke \& Ley 2004, Chen \& Greene 2004, Ponce et al. 2009). In response to cytokines, such as TNF, NFKB1 is liberated from its inhibitory protein NFKBIA in the cytoplasm, and thus enabling its translocation into the nucleus, where it activates its target genes, one of which is MMP9 (Pahl 1999). Another mechanism possibly involved in the MMPs stimulation is through the TNF union to its receptor TNFRSF1B that may also activate the AP-1 pathway, an element present in most of the MMP gene promoters (Sternlicht \& Werb 2001, Yan \& Boyd 2007).

The fact that TNF produced a strong augmentation of ICAM1 protein in both endometrial cell homogenates is in accord with other studies (Rothlein et al. 1988, Vigano et al. 1994, Thomson et al. 1999, Wu et al. 2004) that demonstrate the strong ICAM1 induction mediated by proinflammatory cytokines in endometrial cultures, stimulation not observed on its mRNA suggesting posttranscriptional regulation of ICAM1 in long period of cell culture. Among the possible pathways by which TNF could mediate this increase is through the NFKB1 pathway, as it has been described in ectopic endometrial lesions in patients with endometriosis (Gonzalez-Ramos et al. 2007). Recently, our group reported the reduced presence and function of the NFKB1 pathway and IL6 mRNA in the ex vivo eutopic endometria taken from endometriosis patients during the late secretory phase (Ponce et al. 2009), and slight induction by TNF on IL6 expression in cultured endometrial explants taken from these patients during the mid-late secretory phase, response not observed in normal endometrial explants (Johnson et al. 2005b) or in isolated stromal cells of endometria from women with endometriosis (MC Johnson 2008, personal communication). Therefore, the paracrine interactions between stromal, epithelial, and endothelial cells in the endometrium, and also between these cells and the extracellular matrix may be essential for mediating the cellular response, and the absence of this environment probably modifies the response observed in vivo.

Besides the positive effect of TNF on ICAM1 protein expression, this cytokine also stimulated an increase in ICAM1 cleavage in both stromal cell cultures, with those from endometriosis patients having a more robust response. These results coincide with previous studies using cytokines such as IL1B and IFNG, which augmented the normal release of sICAM1 in endometrial stromal cells, with the concentration also significantly greater in cell cultures from ectopic and eutopic endometria of patients with endometriosis than in controls (Somigliana et al. 1996, Wu et al. 2004, Mangioni et al. 2005). It is possible that the increased cleavage of ICAM1 could be mediated by activation of proteases such as MMPs, which are strongly activated by various cytokines, including TNF (Curry \& Osteen 2003). Some researchers have suggested that the release of adhesion molecules like ICAM1 may be a mechanism for breaking adhesive interactions between cells contributing to the increased invasiveness observed in this disease (Gearing et al. 1992).

The positive association between sICAM1 and active enzymes found in the presence of TNF in both control and endometriosis cells and in the absence of TNF in endometriosis cells, together with the suppression of 
this stimulatory effect by the competitive inhibitor GM6001, suggests that these enzymes might be involved in the release of ICAM1. Only the catalytic domain of MMP9 could significantly induce ICAM1 cleavage, and although MMP1 also induces its release, the results were weak, probably due to the partial degradation of the commercial MMP1 active peptide. Moreover, the aminoacidic sequence of the ICAM1 extracellular domain recognized by MMP9, but also a binding site for proMMP9 has been described in tumor cells resistant to the cytotoxic action of NK cells, which makes the proenzyme available to other proteases for its activation with the posterior ICAM1 cleavage from the cell surface (Fiore et al. 2002). One of the proteases that can activate proMMP9 is MMP1, which also may be bound to the domain I of the ITGA2 present on the cell surface (Sternlicht \& Werb 2001). The fact that proMMP9 secretion was strongly increased by TNF in both control and endometriosis cell cultures, but that its basal level was significantly reduced compared with MMP9 and proMMP9 dimer, mainly in endometriosis cells, supports the hypothesis that other proteases may be contributing to the activation of this enzyme.

Given that GM6001 is not an exclusive inhibitor of MMP1 and MMP9, it is not possible to clarify the causeeffect relation in ICAM1 cleavage, and other strategies will be necessary, such as specific MMP1 or MMP9 interference RNA silencing. Also, the results obtained suggest that other proteases may participate in the processing of ICAM1; on this topic, kidney fibroblasts that coexpress ICAM1 and the metalloproteinase ADAM17 augment sICAM1 concentration, an effect that is blocked when this enzyme is inhibited (Tsakadze et al. 2006). ADAM17 participates in the cleavage of several molecules that include proTNF and its membrane receptors TNFRSF1A and TNFRSF1B, contributing to the availability and half life of the cytokine (Zheng et al. 2004, Murphy 2008). Moreover, this enzyme is importantly increased in eutopic endometria from endometriosis patients compared with those from control patients (Johnson et al. 2005b), and therefore, it could have a plausible role in this mechanism.

The similar results obtained in proliferative and secretory endometrial stromal cells at passages 2-3 cultured in the absence of ovarian steroids suggest the loss during culture of their characteristic regulation on endometria in vivo; then, and similarly to other authors (Vigano et al. 2001, Utsunomiya et al. 2008), we analyzed all data together. As it has been widely reported, the stromal cells treatment with steroids induces their differentiation to predecidual stromal cells in vitro allowing the molecule synthesis expressed during the uterine receptive window (Sugino et al. 2000, White et al. 2005). Interestingly, the molecular differences were maintained in stromal cells derived from control and from endometriosis endometria during cultures, indicating that eutopic endometria differ biochemically from normal tissue as Matsuzaki et al. $(2005,2006)$ previously reported. Moreover, in the baboon endometriosis model, it has been reported that the early events and the progression of this disease with induction of molecular changes at the eutopic and ectopic endometria probably maintained by the peritoneal and endometrial microenvironments, and the communication between peritoneal and uterine cavities in both directions that facilitate the transference of substance in baboons (Hastings \& Fazleabas 2006) and women (Bulletti et al. 2004).

In summary, this pathology, although considered benign, involves invasive events similar to metastasis in which the ectopic endometrial tissue degrades the extracellular matrix during penetration into the peritoneal mesothelium, with augmented MMPs expression and activity in endometriotic lesions and peritoneal fluid, establishment of blood supply and secretion of growth factors, cytokines and hormones that facilitate its permanence in abnormal locations. The MMP9 deregulation, the TNF effects on MMP1 and proMMP9 secretion and also on the expression, and cleavage of ICAM1 might explain the ectopic tissue resistance to immune system recognition, and its augmented proteolytic activity contributing to the pathophysiology of endometriosis and its high recurrence in these patients.

\section{Materials and Methods}

\section{Subjects}

Samples included endometria from ten eumenorrheic reproductively normal women without endometriosis who underwent laparoscopic tubal sterilization or hysterectomy for a benign nonendometrial gynecologic condition (control group), and ten eutopic endometria from women undergoing laparoscopy for diagnosis of endometriosis and later surgically

Table 3 Clinical characteristics of women without (control) and with endometriosis.

\begin{tabular}{llll}
\hline & Control $(n=10)$ & Endometriosis $(n=10)$ & $P$ value \\
\hline Age (mean \pm S.E.M.) & $38.4 \pm 0.5$ & $35.2 \pm 0.7$ & 0.22 \\
BMI (mean \pm S.E.M.) & $25.9 \pm 0.5 \mathrm{~kg} / \mathrm{m}^{2}$ & $26.08 \pm 0.5 \mathrm{~kg} / \mathrm{m}^{2}$ & 0.93 \\
Parity (range) & $1-5$ & $0-2$ & $\mathrm{ND}$ \\
Menstrual cycle: proliferative/secretory & $4 / 6$ & $3 / 7$ & $\mathrm{ND}$ \\
Endometriotic lesion location: peritoneal/ovarian cyst & - & $9 / 1$ & - \\
Stage I-II/stage III-IV (ASRM) & - & $6 / 4$ & - \\
\hline
\end{tabular}

$\mathrm{ND}$, not determined. 
confirmed. Table 3 shows the clinical characteristics of the women with and without endometriosis. The age and body mass index (BMI) of controls and patients were not statistically different, and endometriotic foci were localized on the peritoneum $(90 \%)$ or in the ovaries $(10 \%)$, and the severity was categorized according to the American Society of Reproductive Medicine guidelines (1997). All the surgeries were done in the San Borja-Arriarán Clinical Hospital.

All participating women signed a written informed consent approved by the Institutional Review Boards of University of Chile and the Metropolitan Central Health Service of Chile. Women with antecedents of hormonal treatment or contraceptives during the previous 6 or 3 months respectively or with neoplastic, endocrine, or infectious diseases were excluded from the present study. Menstrual cycle stage of the endometrial samples was determined according to the histological Noyes' criteria (Noyes et al. 1975) by an experienced pathologist, resulting in four control and three endometriosis samples in the proliferative phase, and six controls and seven endometriosis samples in the secretory phase.

\section{Tissue sampling, isolation, and endometrial stromal cell culture}

Endometrial samples from controls and patients were obtained with suction pipelle from the uterine fundus during surgery and were transported at $4{ }^{\circ} \mathrm{C}$ in sterile PBS. The tissue was washed with cold PBS to remove blood clots and cut into fragments where one piece was used for histological analysis. The endometrial biopsies were chopped and then digested with collagenase type I $(1 \mathrm{mg} / \mathrm{ml}$; Worthington Biochemical Corp., Freehold, NJ, USA), dissolved in phenol red free DMEM (Invitrogen Life Technologies) and supplemented with DNase I $\left(25 \mu \mathrm{g} / \mathrm{ml}\right.$; Sigma Co.) at $37^{\circ} \mathrm{C}$ with agitation for $60 \mathrm{~min}$. After resting for $10 \mathrm{~min}$, the supernatant was filtered through a $100 \mu \mathrm{m}$ pore nylon mesh (Becton Dickinson Co., Franklin Lakes, NJ, USA) to exclude the rest of the remaining glands. Then, it was centrifuged, washed twice with enzyme-free medium, and suspended in $1 \mathrm{ml}$ culture media (DMEM/MCDB-105 (Sigma, 3:1 v/v), enriched with 2\% fetal bovine serum (FBS; Invitrogen), $0.25 \mu \mathrm{g} / \mathrm{ml}$ ascorbic acid (Sigma), insulin-transferrin-selenium solution, $2 \mathrm{mmol} / \mathrm{l}$ glutamax-l, $0.25 \mu \mathrm{g} / \mathrm{ml}$ fungizone, $100 \mathrm{IU} / \mathrm{ml}$ penicillin and $5 \mathrm{mg} / \mathrm{ml}$ streptomycin (Invitrogen)). Cells were seeded on $75 \mathrm{~cm}^{2}$ culture flasks and kept at $37^{\circ} \mathrm{C}$ in a humidified atmosphere of $5 \% \mathrm{CO}_{2}$ /air until confluence. After that, the cells were detached with trypsin-EDTA (Invitrogen), reseeded once or twice in culture flasks and then, in six-well plates or Petri dishes (Orange Scientific, Braine-l'Alleud, Belgium) for RNA or protein studies respectively until reaching $80 \%$ confluence. The cells were deprived of FBS for $24 \mathrm{~h}$ in defined medium (DMEM, 0.1\% (w/v) BSA (Sigma), $26 \mathrm{mmol} / \mathrm{l} \mathrm{NaHCO}_{3}$, $25 \mathrm{mmol} / \mathrm{l} \mathrm{HEPES}, 100 \mathrm{IU} / \mathrm{ml}$ penicillin, $5 \mathrm{mg} / \mathrm{ml}$ streptomycin) and incubated for 24 or $48 \mathrm{~h}$ in fresh defined media in the presence or absence of TNF $(10 \mathrm{ng} / \mathrm{ml}$; Chemicon International, Inc., Temecula, CA, USA) and MMP1 $(0.7 \mathrm{nmol} / \mathrm{l}$; human recombinant catalytic domain; Biomol International, Plymouth Meeting, PA, USA), MMP9 (1.3 nmol/l; human recombinant catalytic domain; Biomol) or GM6001 (100 $\mu \mathrm{mol} / \mathrm{l}$; Biomol). GM6001 was applied $30 \mathrm{~min}$ prior to TNF addition because it acts as a competitive inhibitor of MMPs by binding to their active site. The enzymes and inhibitor concentrations were previously determined in a dose-response curve in accordance with manufacturer's instructions and some reports (Galardy et al. 1994, Mccawley \& Matrisian 2001). No significant differences were found between proliferative and secretory endometrial stromal cells (2-3 passages) for any molecule (MMP1, MMP9, ICAM1, and sICAM1) studied.

The purity of the isolated stromal cells was evaluated by immunocytochemistry using antibodies against vimentin ( $2 \mu \mathrm{g} / \mathrm{ml}$, monoclonal, Calbiochem, Biosciences Inc., La Jolla, CA, USA), cytokeratin (2 $\mu \mathrm{g} / \mathrm{ml}$, monoclonal, Calbiochem), and PTPRC (CD45; 1:50 polyclonal, Dako Corp., Carpinteria, CA, USA) resulting in $>96 \%$ purity for endometrial stromal cells, $<4 \%$ for endometrial epithelial cells, and $0 \%$ for leucocytes in the cultures.

\section{RNA preparation, cDNA synthesis, RT-PCR}

Total RNA was isolated from stromal cell cultures using TRIzol (Invitrogen) plus $2.5 \mu \mathrm{g} / \mathrm{ml}$ glycogen (Chemicon), according to manufacturer's instructions; then, the purified RNA was resuspended in diethylpyrocarbonate-treated water, and its integrity was confirmed by agarose-formaldehyde electrophoresis. cDNA was synthesized from total RNA previously treated with DNAse DNA-free (Ambion Inc., Austin, TX, USA), according to indications of the supplier. Two microgram of RNA free from polluting DNA were incubated with random primers (Invitrogen), RNAse OUT (Invitrogen) and the $U$ RevertAid H Minus M-MuLV RT (Fermentas AB, Vilnius, Lituania) for $60 \mathrm{~min}$ at $42{ }^{\circ} \mathrm{C}$, following the indications of the supplier.

The amplification of MMP1, MMP9 and ICAM1 was made using specific primers: MMP1 (587 bp, accession NM 002421) upstream 5'-GGA GAT CAT CGG GAC AAC T-3', downstream 5'GGG TAT CCG TGT AGC ACA TTC-3' (Zhang et al. 1998); MMP9 (391 bp, accession NM 004994) upstream 5'-GAG GAA TAC CTG TAC CGC TAT G-3', downstream 5'-CAA ACC GAG TTG GAA CCA CG-3' (Collette et al. 2006), and ICAM1 (943 bp, accession NM 000201) upstream 5'-GTC CCC CTC AAA AGT CAT-3', downstream 5'- AAC CCC ATT CAG CGT CAC CT-3' (Vigano et al. 1998). Two microlitres of cDNA per reaction were adjusted to a total volume of $25 \mu \mathrm{l}$ by adding PCR buffer containing $\mathrm{MgCl}_{2}$ (3 mmol// for $M M P 1,1 \mathrm{mmol} / \mathrm{l}$ for MMP9, and $2 \mathrm{mmol} / \mathrm{l}$ for ICAM1), Taq DNA polymerase $(0.125 \cup$ for $M M P 1,0.625 \cup$ for $M M P 9$, and $0.2 \cup$ for ICAM1), $0.4 \mathrm{mmol} / \mathrm{l}$ of each primer, and $0.25 \mathrm{mmol} / \mathrm{l} \mathrm{dNTP}$. The reaction was performed in thermal cycler model MyCycler Version 1.065 (Bio-Rad) at $94{ }^{\circ} \mathrm{C}$ for $60 \mathrm{~s}$ (denaturation), at $62{ }^{\circ} \mathrm{C}$ for $M M P 1$ and at $55^{\circ} \mathrm{C}$ for MMP9, ICAM1 for $60 \mathrm{~s}$ (annealing), and at $72{ }^{\circ} \mathrm{C}$ for $60 \mathrm{~s}$ (extension). The linearity of each gene was determined previously in stromal cell cultures and was 35, 38, and 34 cycles for MMP1, MMP9, and ICAM1 respectively. As internal control, $18 \mathrm{~S}$ rRNA was amplified routinely in all cDNA synthesis in the condition previously reported (Schmittgen \& Zakrajsek 2000, Johnson et al. 2005a). The amplified products were solved in agarose gel in 
a $1.0 \%(\mathrm{w} / \mathrm{v})$ that included ethidium bromide, and the semiquantitation of PCR products was performed by image analysis (Kodak EDAS 290 Electrophoresis Documentation and Analysis System, Kodak 1D Image Analysis Software). Their identification was confirmed by sequencing (Macrogen Inc., Seoul, Republic of Korea).

\section{Western blot for ICAM1 and MMP1}

Cytosolic protein extracts were obtained as indicated previously with some modifications. Briefly, after recovering the supernatant, adhered cells were washed with PBS and then scrapped with lysis buffer, left to rest for 15 min on ice and then $0.05 \%(\mathrm{v} / \mathrm{v}) \mathrm{NP}-40$ was added followed by agitation for $15 \mathrm{~s}$ and centrifugation for $2 \mathrm{~min}$ at $17300 \mathrm{~g}$ at $4{ }^{\circ} \mathrm{C}$. The supernatant (cytosolic fraction that included plasmatic membrane) was recovered in a fresh tube, and the protein concentration was measured using the Bradford assay (Bradford Assay Reagent, Bio-Rad). Forty micrograms of proteins were denatured with loading buffer containing dithiothreitol (DTT), resolved on an $8 \%$ polyacrylamide gel by PAGE at $80 \mathrm{~V}$ for $150 \mathrm{~min}$ and electrotransferred onto nitrocellulose membranes (Bio-Rad) at $80 \mathrm{~V}$ for $120 \mathrm{~min}$ at $4{ }^{\circ} \mathrm{C}$. Then, membranes were blocked with $5 \%(\mathrm{w} / \mathrm{v}) \mathrm{BSA}$ in TTBS buffer $(20 \mathrm{mmol} / \mathrm{l}$ Tris- $\mathrm{HCl} \mathrm{pH} 7.6,137 \mathrm{mmol} / \mathrm{l} \mathrm{NaCl}$, $0.1 \%(\mathrm{v} / \mathrm{v})$ Tween 20$)$ for $60 \mathrm{~min}$, washed thrice for $10 \mathrm{~min}$ each with TTBS, and incubated with the primary mouse MABs for ICAM1 (1:1500; BD Biosciences, San Jose, CA, USA), MMP1 (1:1000; Chemicon) or ACTB (1:15000; Sigma) for $18 \mathrm{~h}$ at $4{ }^{\circ} \mathrm{C}$. After washes, the membranes were incubated with secondary antibody conjugated with peroxidase (1:10 000) for $60 \mathrm{~min}$ at room temperature and then incubated in developing solution for chemiluminescence (Pierce ECL Western Blotting Substrate, Pierce, IL, USA). The images were captured with Discovery 10 gD (Ultralum, Claremont, CA, USA) using UltraQuant (version 6.0.0.344) software, analyzed with Kodak 1D Image, and normalized with ACTB.

\section{Zymography for MMP1 and MMP9}

The activities of MMP1 and MMP9 were determined in the cell culture medium. Fifteen microlitres of the medium incubated in loading buffer without DTT for $30 \mathrm{~min}$ at room temperature were resolved in $8 \%$ polyacrylamide gel copolymerized with gelatin $(1 \mathrm{mg} / \mathrm{ml}$, Sigma) or in $10 \%$ polyacrylamide gel copolymerized with casein $(1 \mathrm{mg} / \mathrm{ml}$, Merck) in similar conditions to those indicated for western blots above. In each electrophoresis run, a molecular weight marker was included, and in gelatin zymography, $0.01 \mu \mathrm{g} / \mu \mathrm{l}$ of latent and active MMP9 purified proteins (Chemicon) were run as internal standards. After the gels were run, they were incubated with Triton X-100 $(2.5 \% \mathrm{v} / \mathrm{v})$ for $20 \mathrm{~min}$ with constant rotating agitation at room temperature and were then incubated in MMP assay buffer $(50 \mathrm{mmol} / \mathrm{l}$ Tris- $\mathrm{HCl} \mathrm{pH} \mathrm{7.4,} 150 \mathrm{mmol} / \mathrm{l}$ $\mathrm{NaCl}, 20 \mathrm{mmol} / / \mathrm{CaCl}_{2}, 0.02 \%(\mathrm{w} / \mathrm{v}) \mathrm{NaN}_{2}$ ) for $24 \mathrm{~h}$ at $37^{\circ} \mathrm{C}$. After the gels were stained and destained, the proteolytic gelatinase and collagenase activities were visualized as defined clear bands on a blue background. The bands were captured and analyzed similarly to PCR products. The zymography results are expressed as arbitrary units regarding the total microgram of proteins loaded (MMP1) or as values normalized to the internal standard (MMP9).

\section{Enzymatic activity assay}

The concentration of active MMP1 secreted into the media was determined in $100 \mu \mathrm{l}$ of media using a Human Active MMP1 Fluorescent Assay kit (R\&D System Inc., Minneapolis, MN, USA), according to the manufacturer's instructions. The relative fluorescence units were determined with an excitation wavelength of $320 \mathrm{~nm}$ and an emission wavelength of $405 \mathrm{~nm}$ using a SpectraMax M5/M5 ${ }^{\mathrm{e}}$ (Molecular Devices Corporation, Sunnyvale, CA, USA). The kit detection limit was $0.052 \mathrm{ng} / \mathrm{ml}$, and the intra and interassay reproducibility was ranged from 9.6 to $10.0 \%$ and from 8.7 to $17.7 \%$ respectively.

\section{ELISA for SICAM1}

The sICAM1 concentration was measured in the media using the Immunoassay Human sICAM1 kit (R\&D System, catalog number BBE1B), according to the manufacturer's instructions. Briefly, $100 \mu \mathrm{l}$ of culture media were incubated for $1.5 \mathrm{~h}$ at room temperature, rinsed 4 times, and $100 \mu$ of substrate were added for $30 \mathrm{~min}$. The reaction was terminated with stopping solution and was measured in a microplate reader (Bio-Rad model 680) at a wavelength of $450 \mathrm{~nm}$ within $30 \mathrm{~min}$. The minimal detectable concentration of sICAM1 was $0.096 \mathrm{ng} / \mathrm{ml}$, and the intra and interassay reproducibility was ranged from 3.3 to $4.8 \%$ and from 6.0 to $10.1 \%$ respectively.

\section{Statistical analysis}

The level of significance was established as $\alpha<0.05$. We tested the normal distribution of the data using the KolmogorovSmirnoff test and using parametric models like unpaired $t$-test when dealing with means and nonparametric tests like the Mann-Whitney $U$ test or the Kruskal-Wallis $H$ test when not dealing with means. Pearson correlation was used to investigate the associations between different variables tested in pooled results for stromal cell cultures from patients with endometriosis and from controls. Pearson tests and linear regression analyzes were applied using the software SPSS 13.0 (SPSS Inc., Chicago, IL, USA). Results are expressed as mean \pm s.E.M.

\section{Declaration of interest}

The authors declare that there is no conflict of interest that could be perceived as prejudicing the impartiality of the research reported.

\section{Funding}

Supported by Fondo Nacional de Ciencias y Tecnología (FONDECYT) \# 1080229, Santiago, Chile and by Sociedad Chilena de Endocrinología y Diabetes (SOCHED) 2007-1. 


\section{Acknowledgements}

The authors are grateful to Fernando Gabler, MD (School of Medicine, University of Chile, Chile) for his role in patient endometrial dating, to Julieta Gonzalez (School of Medicine, University of Chile, Chile) and Fabian Arechavaleta-Velasco, PhD (Hospital de Ginecobstetricia Luis Castelazo Ayala, Mexico) for the zymography technics, and to all the women who donated tissue: without their generous contribution, this study would not have been possible.

\section{References}

American Society for Reproductive Medicine 1997 Revised American Society for Reproductive Medicine classification of endometriosis: 1996. Fertility and Sterility 67 817-821.

Beinke S \& Ley SC 2004 Functions of NF-kappaB1 and NF-kappaB2 in immune cell biology. Biochemical Journal 382 393-409.

Bulletti C, Dez D, Setti PL, Cicinelli E, Polli V \& Flamigni C 2004 The patterns of uterine contractility in normal menstruating women: from physiology to pathology. Annals of the New York Academy of Sciences 1034 64-83.

Bulun SE 2009 Endometriosis. New England Journal of Medicine 360 268-279.

Chakraborti S, Mandal M, Das S, Mandal A \& Chakraborti T 2003 Regulation of matrix metalloproteinases: an overview. Molecular and Cellular Biochemistry 253 269-285.

Chakrabarti S, Zee JM \& Patel KD 2006 Regulation of matrix metalloproteinase-9 (MMP-9) in TNF-stimulated neutrophils: novel pathways for tertiary granule release. Journal of Leukocyte Biology 79 214-222.

Chen LF \& Greene WC 2004 Shaping the nuclear action of NF-kappaB. Nature Reviews. Molecular Cell Biology 5 392-401.

Cheong YC, Shelton JB, Laird SM, Richmond M, Kudesia G, Li TC \& Ledger WL 2002 IL-1, IL-6 and TNF- $\alpha$ concentrations in the peritoneal fluid of women with pelvic adhesions. Human Reproduction 17 69-75.

Chung HW, Wen Y, Chun SH, Nezhat C, Woo BH \& Lake Polan M 2001 Matrix metalloproteinase- 9 and tissue inhibitor of metalloproteinase-3 mRNA expression in ectopic and eutopic endometrium in women with endometriosis: a rationale for endometriotic invasiveness. Fertility and Sterility 75 152-159.

Collette T, Bellehumeur C, Kats R, Maheux R, Mailloux J, Villeneuve M \& Akoum A 2004 Evidence for an increased release of proteolytic activity by the eutopic endometrial tissue in women with endometriosis and for involvement of matrix metalloproteinase-9. Human Reproduction 19 1257-1264.

Collette T, Maheux R, Mailloux J \& Akoum A 2006 Increased expression of matrix metalloproteinase- 9 in the eutopic endometrial tissue of women with endometriosis. Human Reproduction 21 3059-3067.

Cramer DW \& Missmer SA 2002 The epidemiology of endometriosis. Annals of the New York Academy of Sciences 955 11-22 (discussion 34-36, 396-406).

Curry TE \& Osteen KG 2003 The matrix metalloproteinase system: changes, regulation, and impact throughout the ovarian and uterine reproductive cycle. Endocrine Reviews 24 428-465.

DeClerck YA, Perez N, Shimada H, Boone TC, Langley KE \& Taylor SM 1992 Inhibition of invasion and metastasis in cells transfected with an inhibitor of metalloproteinases. Cancer Research 52 701-708.

Dejana E 2004 Endothelial cell-cell junctions: happy together. Nature Reviews. Molecular Cell Biology 5 261-270.

Domeij H, Modeer T, Quezada HC \& Yucel-Lindberg T 2005 Cell expression of MMP-1 and TIMP-1 in co-cultures of human gingival fibroblasts and monocytes: the involvement of ICAM-1. Biochemical and Biophysical Research Communications 338 1825-1833.

Fan T, Zhao Q, Chen JJ, Chen WT \& Pearl ML 2009 Clinical significance of circulating tumor cells detected by an invasion assay in peripheral blood of patients with ovarian cancer. Gynecologic Oncology 112 185-191.
Fiore E, Fusco C, Romero P \& Stamenkovic I 2002 Matrix metalloproteinase 9 (MMP-9/gelatinase B) proteolytically cleaves ICAM-1 and participates in tumor cell resistance to natural killer cell-mediated cytotoxicity. Oncogene 21 5213-5223.

Fishman DA, Bafetti LM, Banionis S, Kearns AS, Chilukuri K \& Stack MS 1997 Production of extracellular matrix-degrading proteinases by primary cultures of human epithelial ovarian carcinoma cells. Cancer 80 1457-1463.

Galardy RE, Cassabonne ME, Giese C, Gilbert JH, Lapierre F, Lopez H, Schaefer ME, Stack R, Sullivan M, Summers B et al. 1994 Low molecular weight inhibitors in corneal ulceration. Annals of the New York Academy of Sciences 732 315-323.

Gavert N, Sheffer M, Raveh S, Spaderna S, Shtutman M, Brabletz T, Barany F, Paty P, Notterman D, Domany E et al. 2007 Expression of L1-CAM and ADAM10 in human colon cancer cells induces metastasis. Cancer Research 67 7703-7712.

Gearing AJ, Hemingway I, Pigott R, Hughes J, Rees AJ \& Cashman SJ 1992 Soluble forms of vascular adhesion molecules, E-selectin, ICAM-1, and VCAM-1: pathological significance. Annals of the New York Academy of Sciences 667 324-331.

Gonzalez-Ramos R, Donnez J, Defrere S, Leclercq I, Squifflet J, Lousse JC \& Langendonckt A 2007 Nuclear factor-kappa B is constitutively activated in peritoneal endometriosis. Molecular Human Reproduction 13 503-509.

Hastings JM \& Fazleabas AT 2006 A baboon model for endometriosis: implications for fertility. Reproductive Biology and Endocrinology 4 S7.

Henriet P, Cornet PB, Lemoine P, Galant C, Singer CF, Courtoy PJ, Eeckhout Y \& Marbaix E 2002 Circulating ovarian steroids and endometrial matrix metalloproteinases (MMPs). Annals of the New York Academy of Sciences 955 119-138.

Hudelist G, Lass H, Keckstein J, Walter I, Wieser F, Wenzl R, Mueller R, Czerwenka K, Kubista E \& Singer CF 2005 Interleukin $1 \alpha$ and tissue-lytic matrix metalloproteinase-1 are elevated in ectopic endometrium of patients with endometriosis. Human Reproduction 20 1695-1701.

Johnson MC, Torres M, Alves A, Bacallao K, Fuentes A, Vega M \& Boric MA 2005a Augmented cell survival in eutopic endometrium from women with endometriosis: expression of c-myc, TGF- $\beta 1$ and bax genes. Reproductive Biology and Endocrinology 345.

Johnson MC, Torres M, Crisosto N, Ponce C, Bacallao K, Gabler F, Fuentes A \& Boric MA 2005b Altered TNF alpha system in eutopic endometria with endometriosis compared to normal endometria. In Human Reproduction, edn 1, pp 823-827. Eds PG Artina \& R Cicciarella. Roma: CIC Edizioni Internationali.

Khan KN, Masuzaki H, Fujishita A, Kitajima M, Sekine I \& Ishimaru T 2004 Differential macrophage infiltration in early and advanced endometriosis and adjacent peritoneum. Fertility and Sterility 81 652-661.

Kokorine I, Nisolle M, Donnez J, Eeckhout Y, Courtoy PJ \& Marbaix E 1997 Expression of interstitial collagenase (matrix metalloproteinase-1) is related to the activity of human endometriotic lesions. Fertility and Sterility 68 246-251.

Kupker W, Schultze-Mosgau A \& Diedrich K 1998 Paracrine changes in the peritoneal environment of women with endometriosis. Human Reproduction Update 4 719-723.

Kyama CM, Debrock S, Mwenda JM \& D'Hooghe TM 2003 Potential involvement of the immune system in the development of endometriosis. Reproductive Biology and Endocrinology 1123.

Lebovic DI, Mueller MD \& Taylor RN 2001 Immunobiology of endometriosis. Fertility and Sterility 75 1-10.

Liu XJ, He YL \& Peng DX 2002 Expression of metalloproteinase-9 in ectopic endometrium in women with endometriosis. Di Yi Jun Yi Da Xue Xue Bаo 22 467-469.

Mangioni S, Vigano P, Florio P, Borghi O, Vignali M, Petraglia F \& Di Blasio AM 2005 Effect of activin A on tumor necrosis factor- $\alpha$ / intercellular adhesion molecule-1 pathway in endometrial stromal cells. European Journal of Obstetrics, Gynecology, and Reproductive Biology $123218-223$.

Matsuzaki S, Canis M, Vaurs-Barriere C, Boespflug-Tanguy O, Dastugue B \& Mage G 2005 DNA, microarray analysis of gene expression in eutopic endometrium from patients with deep endometriosis using laser capture microdissection. Fertility and Sterility 84 1180-1190. 
Matsuzaki S, Canis M, Pouly JL, Botchorishvili R, Dechelotte PJ \& Mage G 2006 Differential expression of genes in eutopic and ectopic endometrium from patients with ovarian endometriosis. Fertility and Sterility $\mathbf{8 6}$ 548-553.

McCawley LJ \& Matrisian LM 2001 Matrix metalloproteinases: they're not just for matrix anymore! Current Opinion in Cell Biology 13 534-540.

Mizumoto H, Saito T, Ashihara K, Nishimura M, Takehara M, Tanaka R, Ito E \& Kudo R 2002 Expression of matrix metalloproteinases in ovarian endometriomas: immunohistochemical study and enzyme immunoassay. Life Sciences 71 259-273.

Murphy AA 2002 Clinical aspects of endometriosis. Annals of the New York Academy of Sciences 955 1-10.

Murphy G 2008 The ADAMs: signalling scissors in the tumour microenvironment. Nature Reviews. Cancer 8 929-941.

Noyes RW, Hertig AT \& Rock J 1975 Dating the endometrial biopsy. American Journal of Obstetrics and Gynecology 122 262-263.

Olson MW, Bernardo MM, Pietila M, Gervasi DC, Toth M, Kotra LP, Massova I, Mobashery S \& Fridman R 2000 Characterization of the monomeric and dimeric forms of latent and active matrix metalloproteinase-9. Differential rates for activation by stromelysin 1. Journal of Biological Chemistry 275 2661-2668.

Oosterlynck DJ, Cornillie FJ, Waer M, Vandeputte M \& Koninckx PR 1991 Women with endometriosis show a defect in natural killer activity resulting in a decreased cytotoxicity to autologous endometrium. Fertility and Sterility $\mathbf{5 6} 45-51$.

Osteen KG, Bruner KL \& Sharpe-Timms KL 1996 Steroid and growth factor regulation of matrix metalloproteinase expression and endometriosis. Seminars in Reproductive Endocrinology 14 247-255.

Pahl HL 1999 Activators and target genes of Rel/NF-kappaB transcription factors. Oncogene 18 6853-6866.

Ponce C, Torres M, Galleguillos C, Sovino H, Boric MA, Fuentes A \& Johnson MC 2009 Nuclear factor kappaB pathway and interleukin- 6 are affected in eutopic endometrium of women with endometriosis. Reproduction 137 727-737.

Rawdanowicz TJ, Hampton AL, Nagase H, Woolley DE \& Salamonsen LA 1994 Matrix metalloproteinase production by cultured human endometrial stromal cells: identification of interstitial collagenase, gelatinase-A, gelatinase- $B$, and stromelysin- 1 and their differential regulation by interleukin- $1 \alpha$ and tumor necrosis factor- $\alpha$. Journal of Clinical Endocrinology and Metabolism 79 530-536.

Rothlein R, Czajkowski M, O'Neill MM, Marlin SD, Mainolfi E \& Merluzzi VJ 1988 Induction of intercellular adhesion molecule 1 on primary and continuous cell lines by pro-inflammatory cytokines, Regulation by pharmacologic agents and neutralizing antibodies. Journal of Immunology 141 1665-1669.

Sampson J 1927 Peritoneal endometriosis due to menstrual dissemination of endometrial tissue into the peritoneal cavity. American Journal of Obstetrics and Gynecology 14 422-469.

Schmittgen TD \& Zakrajsek BA 2000 Effect of experimental treatment on housekeeping gene expression: validation by real-time, quantitative RT-PCR. Journal of Biochemical and Biophysical Methods 46 69-81.

Sillem M, Prifti S, Koch A, Neher M, Jauckus I \& Runnebaum B 2001 Regulation of matrix metalloproteinases and their inhibitors in uterine endometrial cells of patients with and without endometriosis. European Journal of Obstetrics, Gynecology, and Reproductive Biology 95 167-174.

Singer CF, Marbaix E, Lemoine P, Courtoy PJ \& Eeckhout Y 1999 Local cytokines induce differential expression of matrix metalloproteinases but not their tissue inhibitors in human endometrial fibroblasts. European Journal of Biochemistry 259 40-45.

Somigliana E, Vigano P, Gaffuri B, Guarneri D, Busacca M \& Vignali M 1996 Human endometrial stromal cells as a source of soluble intercellular adhesion molecule (ICAM)-1 molecules. Human Reproduction 11 1190-1194.

Sternlicht MD \& Werb Z 2001 How matrix metalloproteinases regulate cell behavior. Annual Review of Cell and Development Biology 17 463-516.
Sugino N, Kashida S, Takiguchi S, Nakamura Y \& Kato H 2000 Induction of superoxide dismutase by decidualization in human endometrial stromal cells. Molecular Human Reproduction 6 178-184.

Szamatowicz J, Laudanski P \& Tomaszewska I 2002 Matrix metalloproteinase- 9 and tissue inhibitor of matrix metalloproteinase-1: a possible role in the pathogenesis of endometriosis. Human Reproduction 17 284-288.

Tabibzadeh S, Kong QF \& Babaknia A 1994 Expression of adhesion molecules in human endometrial vasculature throughout the menstrual cycle. Journal of Clinical Endocrinology and Metabolism 79 1024-1032.

Taraboletti G, D'Ascenzo S, Borsotti P, Giavazzi R, Pavan A \& Dolo V 2002 Shedding of the matrix metalloproteinases MMP-2, MMP-9, and MT1MMP as membrane vesicle-associated components by endothelial cells. American Journal of Pathology 160 673-680.

Thomson AJ, Greer MR, Young A, Boswell F, Telfer JF, Cameron IT, Norman JE \& Campbell S 1999 Expression of intercellular adhesion molecules ICAM-1 and ICAM-2 in human endometrium: regulation by interferon-gamma. Molecular Human Reproduction 5 64-70.

Tsakadze NL, Sithu SD, Sen U, English WR, Murphy G \& D'Souza SE 2006 Tumor necrosis factor- $\alpha$-converting enzyme (TACE/ADAM-17) mediates the ectodomain cleavage of intercellular adhesion molecule-1 (ICAM-1). Journal of Biological Chemistry 281 3157-3164.

Ulukus M, Cakmak H \& Arici A 2006 The role of endometrium in endometriosis. Journal of the Society for Gynecologic Investigation 13 $467-476$.

Utsunomiya H, Cheng YH, Lin Z, Reierstad S, Yin P, Attar E, Xue Q, Imir G, Thung S, Trukhacheva E et al. 2008 Upstream stimulatory factor-2 regulates steroidogenic factor-1 expression in endometriosis. Molecular Endocrinology 22 904-914.

Vigano P, Pardi R, Magri B, Busacca M, Di Blasio AM \& Vignali M 1994 Expression of intercellular adhesion molecule-1 (ICAM-1) on cultured human endometrial stromal cells and its role in the interaction with natural killers. American Journal of Reproductive Immunology 32 $139-145$.

Vigano P, Gaffuri B, Somigliana E, Busacca M, Di Blasio AM \& Vignali M 1998 Expression of intercellular adhesion molecule (ICAM)-1 mRNA and protein is enhanced in endometriosis versus endometrial stromal cells in culture. Molecular Human Reproduction 4 1150-1156.

Vigano P, Somigliana E, Di Blasio AM, Cozzolino S, Candiani M \& Vignali M 2001 Suppression of natural killer cell function and production of soluble ICAM-1: endometrial stroma versus melanoma. American Journal of Reproductive Immunology 46 342-348.

White CA, Dimitriadis E, Sharkey AM \& Salamonsen LA 2005 Interleukin11 inhibits expression of insulin-like growth factor binding protein-5 mRNA in decidualizing human endometrial stromal cells. Molecular Human Reproduction 11 649-658.

Wu MH, Yang BC, Lee YC, Wu PL \& Hsu CC 2004 The differential expression of intercellular adhesion molecule-1 (ICAM-1) and regulation by interferon-gamma during the pathogenesis of endometriosis. American Journal of Reproductive Immunology 51 373-380.

Yan C \& Boyd DD 2007 Regulation of matrix metalloproteinase gene expression. Journal of Cellular Physiology 211 19-26.

Zhang J, Nie G, Jian W, Woolley DE \& Salamonsen LA 1998 Mast cell regulation of human endometrial matrix metalloproteinases: a mechanism underlying menstruation. Biology of Reproduction 59 693-703.

Zheng Y, Saftig P, Hartmann D \& Blobel C 2004 Evaluation of the contribution of different ADAMs to tumor necrosis factor $\alpha$ (TNF $\alpha)$ shedding and of the function of the TNF $\alpha$ ectodomain in ensuring selective stimulated shedding by the TNF $\alpha$ convertase (TACE/ADAM17). Journal of Biological Chemistry 279 42898-42906.

Received 14 May 2009

First decision 19 June 2009

Accepted 6 August 2009 